\section{Auxin, Wounding, and Propagation Medium Affect Rooting Response of Stem Cuttings of Arbutus andrachne}

\author{
Mohammed M. Al-Salem and Nabila S. Karam ${ }^{1}$ \\ Faculty of Agriculture, Jordan University of Science and Technology, P.O. \\ Box 3030, Irbid, Jordan
}

Additional index words. Eastern strawberry tree, indole-3-butyric acid, naphthaleneacetic acid

\begin{abstract}
Stem cuttings of Arbutus andrachne $\mathrm{L}$. were taken from basal or terminal portions of branches in October and treated with acid or salt forms of IBA or NAA at several concentrations. Also, the effects of wounding and propagation medium were assessed. Auxin was necessary for root formation, IBA acid being most effective. In general, salt forms of IBA and NAA were less effective than acid forms. Concentration of auxin had a significant effect on rooting regardless of auxin type or chemical form. The greatest rooting percentage, root number, length, and fresh and dry weights were exhibited by basal cuttings treated with 24 mM IBA. Position of the cutting on the branch did not affect rooting except when the IBA acid form was used; basal cuttings were then superior to terminal ones. Wounding, by making two opposite longitudinal incisions at the base of the cutting, increased rooting. The propagation medium had a significant effect on adventitious root formation, which was enhanced with increasing perlite percentage in the medium up to $100 \%$. Chemical names used:1H-indole-3-butyric acid (IBA); $\alpha$ naphthaleneacetic acid (NAA).
\end{abstract}

Arbutus andrachne is an evergreen tree found in pine and evergreen oak forests in Jordan (Al-Tellawi, 1989). This tree has potential use as a landscape plant because of its ornamental features, which include twisted stems and branches, leathery evergreen foliage, ornamental flowers, decorative fruits, and peeling reddish-brown bark. To introduce this plant into the landscape industry, a feasible propagation method should be developed. Propagation of Arbutus menziesii Pursh. (Hartmann et al., 1990) and Arbutus unedo L. (Stuart, 1979) by stem cuttings is documented. However, to our knowledge, no work has been done on propagation of $A$. andrachne by stem cuttings. Therefore, the objective of this study was to determine the influence of type, chemical formulation, and concentration of auxin on rooting of $A$. andrachne stem cuttings taken from two branch positions. The effects of wounding of cutting bases and propagation medium on rooting were also assessed.

\section{Materials and Methods}

Common procedures. Shoots $25-30 \mathrm{~cm}$ long were collected from a 25 -year-old tree in

Received for publication 20 Mar. 2000. Accepted for publication 14 Nov. 2000. We acknowledge the Deanship for Scientific Research at Jordan Univ. of Science and Technology (JUST) for funding this project. Sincere appreciation goes to Dr. Hani Ghosheh (JUST) for his guidance in statistical analysis. The cost of publishing this paper was defrayed in part by the payment of page charges. Under postal regulations, this paper therefore must be hereby marked advertisement solely to indicate this fact. ${ }^{1}$ To whom reprint requests should be addressed. Email address:karam@just.edu.jo its natural habitat $\left(32^{\circ} 11^{\prime}\right.$ to $32^{\circ} 24^{\prime} \mathrm{N}$ lat., $35^{\circ} 36^{\prime}$ to $35^{\circ} 54^{\prime} \mathrm{E}$ long., $960 \mathrm{~m}$ above sea level, $574 \mathrm{~mm}$ average annual rainfall). Shoots were pooled, randomized, and trimmed just below the lowest bud. From these shoots, basal and terminal cuttings were prepared. Cuttings were trimmed to three leaves, cut to $12 \mathrm{~cm}$, and wounded, unless otherwise mentioned, by making two opposite longitudinal incisions $\approx 2 \mathrm{~cm}$ long at the cutting base. The basal $1 \mathrm{~cm}$ of each cutting was immersed in the tested solution for $5 \mathrm{~s}$. Cuttings were then inserted to a 5-cm depth into a raised greenhouse bench containing 1 sphagnum peatmoss : 2 perlite $(\mathrm{v} / \mathrm{v})$, unless otherwise mentioned. Cuttings were maintained under natural photoperiod with daily mist, which was operated for $10 \mathrm{~s}$ every $15 \mathrm{~min}$ from 0800 to $1800 \mathrm{HR}$. The temperature of the propagation medium was maintained at $24 \pm 2{ }^{\circ} \mathrm{C}$ and air temperature at $22 \pm 2{ }^{\circ} \mathrm{C}$.

Cuttings were sprayed initially and weekly thereafter with alternating $1.8 \mathrm{~g} \cdot \mathrm{L}^{-1}$ methyl 1(butylcarbamoyl)-2-benzimidazole carbamate (benomyl) (VAPCO, Amman, Jordan) and 2.4 $\mathrm{g} \cdot \mathrm{L}^{-1}$ tetrahydro-2-[(trichloromethyl)thiol] $-1 \mathrm{H}$ isoindole-1,3(2H)-dione (captan) (VAPCO). The propagation medium was also drenched with $0.3 \mathrm{~g} \cdot \mathrm{L}^{-1}$ benomyl before inserting cuttings.

For each experiment, 14 cuttings per treatment were arranged in a completely randomized design. Two months after sticking cuttings, data were recorded on rooting percentage, and root number, length, and fresh and dry weights. Cuttings with a minimum of one root at least $1 \mathrm{~cm}$ long were considered as rooted. Root dry weight was determined by weighing roots after oven drying at $70{ }^{\circ} \mathrm{C}$ for $48 \mathrm{~h}$.
Data for each experiment were subjected to analysis of variance (ANOVA) using the General Linear Models procedure using SAS (Statistical Analysis System) (SAS Institute, 1995). Mean separation was performed using the least significant difference (LSD) method at $P \leq$ 0.05 . Percentage data were arcsine transformed before performing ANOVA.

Effects of cutting position, and type, chemical formulation, and concentration of auxin. Cuttings were taken from current season shoots collected in October. The bases of basal and terminal cuttings were dipped in solutions of IBA (acid form) (5-48 mM). Three other experiments were conducted using NAA (acid form), K-IBA, or K-NAA solutions at the same range of concentrations. Reagent grade auxin was dissolved in 50\% ethanol for the acid form or distilled water for the potassium salt. A control treatment was included in which cuttings were dipped in 50\% ethanol (for the acid form) or distilled water (for the salt form).

Effect of wounding. Cuttings were taken from previous season shoots collected in February. Basal cuttings were wounded as previously mentioned; nonwounded cuttings were used as a control. Cuttings were treated with the acid form of IBA at 24 or $36 \mathrm{~mm}$. The former concentration was chosen since it resulted in the greatest rooting percentage and the latter because the cuttings were woodier than those used in the previous experiment.

Effect of propagation medium. Cuttings were taken from previous season shoots collected in February. Basal cuttings were wounded and treated with the acid form of IBA at 24 or $36 \mathrm{~mm}$. Cuttings were inserted in one of five propagation media: perlite; $1 \mathrm{sph}$ agnum peatmoss : 3 perlite $(\mathrm{v} / \mathrm{v}) ; 1$ sphagnum peatmoss : 1 perlite $(\mathrm{v} / \mathrm{v}) ; 3$ sphagnum peatmoss : 1 perlite $(\mathrm{v} / \mathrm{v})$; or vermiculite.

\section{Results and Discussion}

Effects of cutting position, and type, chemical formulation, and concentration of auxin. Auxin was essential for promoting root formation in A. andrachne; cuttings in the control treatments failed to produce any roots regardless of cutting position. Maximum rooting percentages for each cutting type and form of auxin were as follows: $24 \mathrm{~mm}$ IBA $(72 \%$ for basal cuttings), $12 \mathrm{~mm}$ IBA ( $29 \%$ for terminal cuttings), 24 mм NAA (14\% for basal and $21 \%$ for terminal cuttings), $24 \mathrm{~mm}$ K-IBA ( $21 \%$ for basal and $14 \%$ for terminal cuttings), and 36 mm K-NAA (14\% for both basal and terminal cuttings). Auxin is essential for rooting of cuttings in several plant species (AlSaqri and Alderson, 1996; Carpenter and Cornell, 1992; Erwin et al., 1997) but not others (Hinesley et al., 1994; Maynard and Bassuk, 1990). The acid form of IBA was the most effective auxin in promoting root formation in the current study. There are conflicting reports on the effectiveness of different auxins, especially when comparing NAA and IBA. Teklehaimanot et al. (1996) reported that $100 \mathrm{mg} \cdot \mathrm{L}^{-1} \mathrm{NAA}$ was more effective than IBA at the same concentration in promoting root formation on stem cuttings of Parika biglobosa 
(Jacq.) Benth. However, IBA was more effective than NAA when the concentration was increased to $200 \mathrm{mg} \cdot \mathrm{L}^{-1}$. In a study with kiwifruit [(Actinidia deliciosa (A.Chev.) C.S.Liang and A.R. Ferguson)], NAA was the most effective auxin in promoting rooting on stem cuttings, whereas IBA had little effect (Testolin and Vitagliano, 1987). In the current study, the acid forms of IBA (maximum rooting of $72 \%$ ) and NAA (maximum rooting of $21 \%$ ) were more effective than the corresponding salts (maximum rooting of $21 \%$ and $14 \%$ for $\mathrm{K}$ IBA and K-NAA, respectively). This may have some commercial implications since the salt forms are more expensive and less effective on a per weight basis than are the pure compounds.

Since the acid form of IBA was the most effective auxin in promoting root formation, only results using this form will be discussed. A significant interaction of cutting position and IBA concentration was detected in rooting response. Analyses of variance performed separately on data for each cutting type indicated significant effects of IBA concentration on rooting percentage for both basal $(P \leq 0.0001)$ and terminal $(P \leq 0.01)$ cuttings (Fig. 1$)$. As concentration of IBA increased, rooting increased up to $72 \%$ at $24 \mathrm{~mm}$ for basal cuttings and $29 \%$ at $12 \mathrm{~mm}$ for terminal ones. Above these concentrations, rooting percentage decreased until rooting was completely suppressed at 48 and $36 \mathrm{~mm}$ for basal and terminal cuttings, respectively. Furthermore, IBA concentration significantly affected root number $(P \leq 0.0001)$, length $(P \leq 0.001)$, fresh weight $(P \leq 0.001)$, and dry weight $(P \leq 0.01)$ for basal cuttings (Figs. 1 and 2 ). The same root parameters for terminal cuttings were also affected $(P \leq 0.05)$ by IBA concentration (Figs. 1 and $2)$; the responses followed patterns similar to those observed in rooting percentage. Auxin concentration has been reported to affect rooting of cuttings in a number of woody species (Al-Saqri and Alderson, 1996; Carpenter and Cornell, 1992; Jull et al., 1994).

In the current study, basal cuttings treated with 24 mм IBA acid rooted better and produced longer roots with greater fresh and dry weights than did terminal ones (Figs. 1 and 2). Nodal position on the shoot influences rooting of stem cuttings; medial and basal cuttings of cabbage rose (Rosa $\times$ centifolia L.) (Al-Saqri and Alderson, 1996) and lateral cuttings of old southern magnolia (Magnolia grandiflora L.) (Perry and Vines, 1972) rooted better than did apical ones.

Effect of wounding. Rooting was significantly affected by wounding (Table 1). Rooting percentage, root number, length, and fresh and dry weights were almost three, six, 10, eight, and eight times, respectively, as great in wounded as in nonwounded cuttings. Treatment with IBA at $24 \mathrm{~mm}$ produced more and longer roots than did IBA at $36 \mathrm{~mm}$ (Table 1). Basal wounding of cuttings was also beneficial for rooting of apple (Malus $\times$ domestica Borkh.) rootstock M.26 (Mackenzie et al., 1986) and Parika biglobosa (Teklehaimanot et al., 1996).

Effect of propagation medium. There was
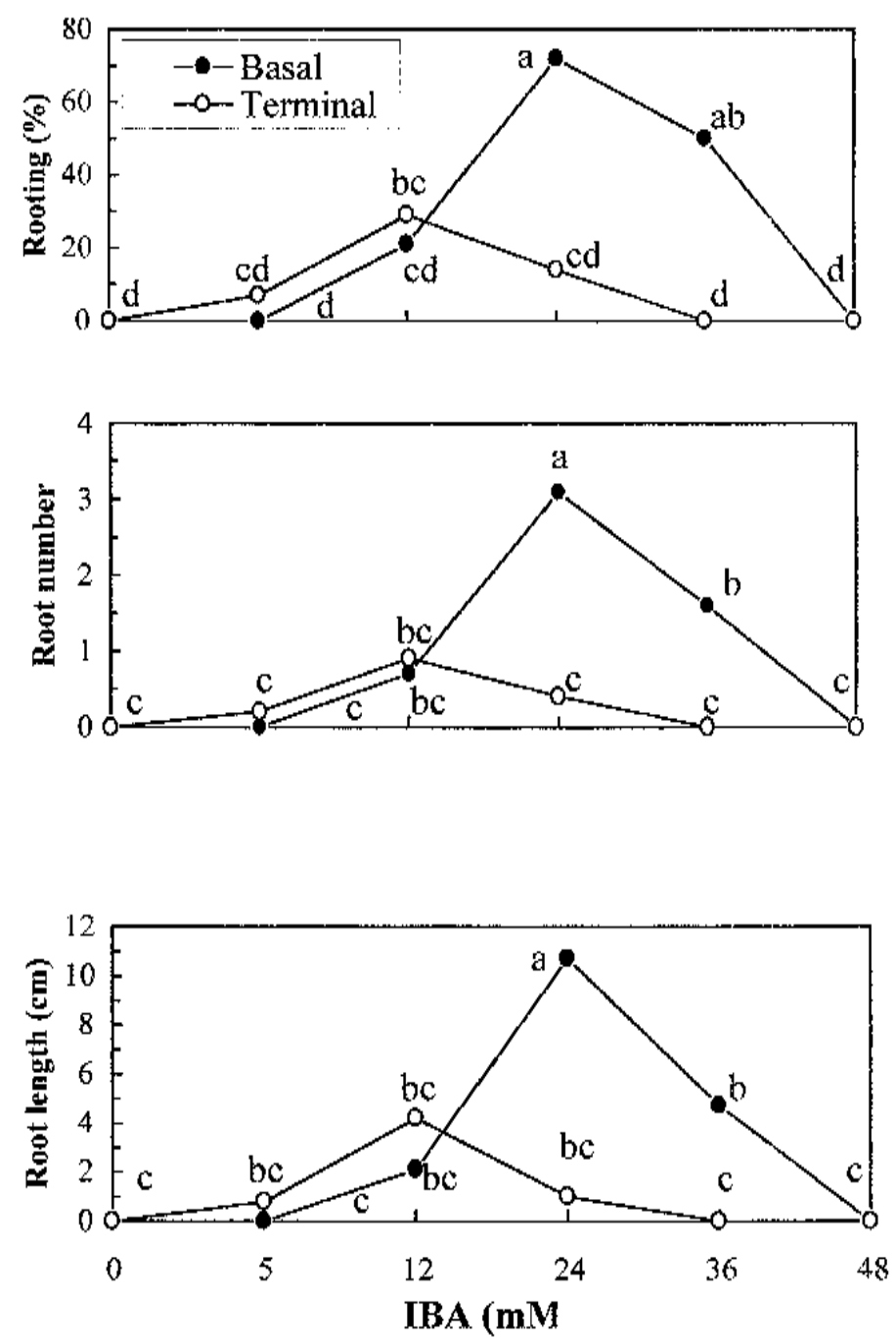

Fig. 1. Percent rooting, root number per cutting, and length of roots (cm) formed on A. andrachne basal and terminal stem cuttings, as affected by IBA concentration (mM) and cutting position on the branch. Mean separation among all treatments by LSD, $P \leq 0.05$.

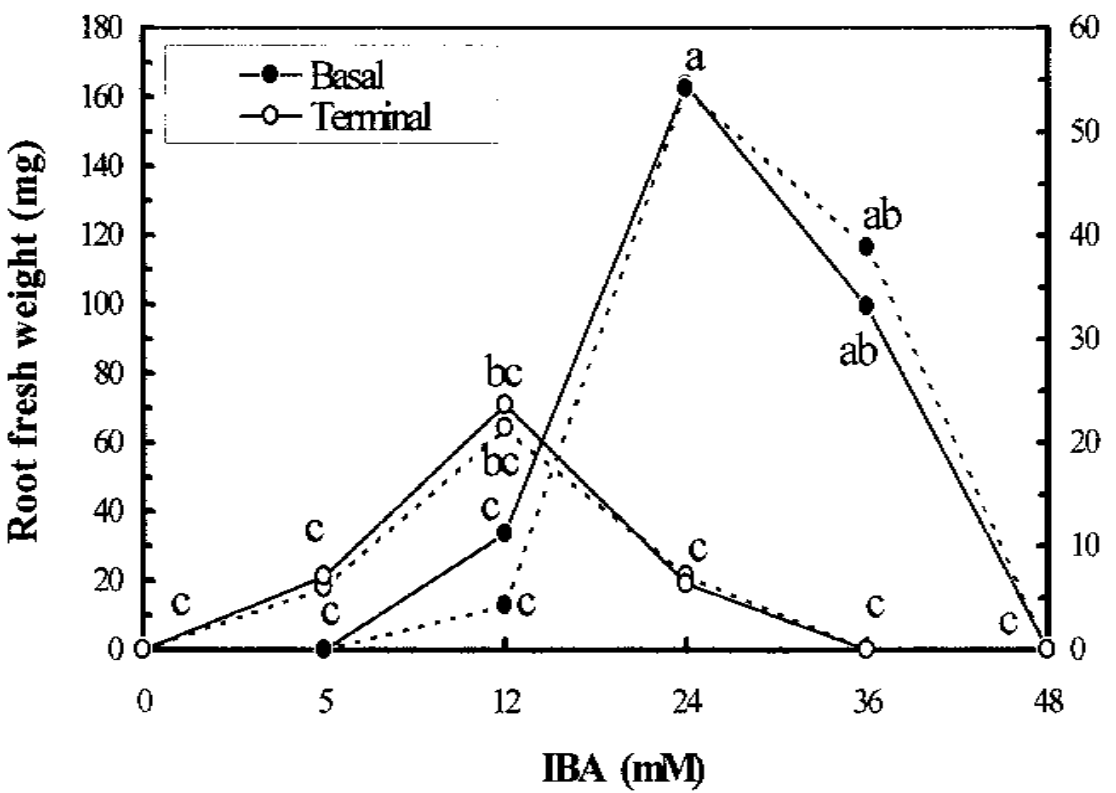

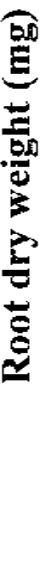

Fig. 2. Fresh (dotted line) and dry (solid line) weight of roots formed per cutting on A. andrachne basal and terminal stem cuttings, as affected by IBA concentration (mM) and position of cutting on the branch. Mean separation among all treatments for each parameter by LSD, $P \leq 0.05$. 
no interaction between medium and IBA concentration. Although rooting percentage was not affected by IBA concentration, all other root parameters were (Table 2). Cuttings treated with $24 \mathrm{~mm}$ IBA produced more and longer roots with greater fresh and dry weights than did those treated with $36 \mathrm{~mm}$. The most effective media were perlite and 1 sphagnum peatmoss : 3 perlite, in which $64 \%$ and $54 \%$ of cuttings rooted, respectively. These propagation media also resulted in production of the greatest root number, length, and fresh and dry weights. The least effective medium was vermiculite; as the percentage of perlite increased, rooting response improved.

In conclusion, A. andrachne may be propagated by stem cuttings taken from the basal portion of shoots in October, wounded at their bases, treated with $24 \mathrm{~mm}$ IBA, and inserted in perlite for 2 months.

\section{Literature Cited}

Al-Saqri, F. and P.G. Alderson. 1996. Effects of IBA, cutting type and rooting media on rooting of Rosa centifolia. J. Hort. Sci. 71:729-737.

Al-Tellawi, A. 1989. Forests in Jordan. Dar AlBashir, Amman, Jordan.

Carpenter, W.J. and J.A. Cornell. 1992. Auxin application duration and concentration govern rooting of Hibiscus stem cuttings. J. Amer. Soc. Hort. Sci. 117:68-74.

Erwin, J.E., D. Schwarze, and R. Donahue. 1997. Factors affecting propagation of Clematis by stem cuttings. HortTechnology 7:408-410.

Hartmann, H.T., D.E. Kester, and F.T. Davies, Jr. 1990. Plant propagation: Principles and practices. 5th ed. Prentice Hall, Englewood Cliffs, N.J.

Hinesley, L.E., F.A. Blazich, and L.K. Snelling. 1994. Propagation of Atlantic white cedar by stem cuttings. HortScience 29:217-219.

Jull, L.G., S.L. Warren, and F.A. Blazich. 1994. Rooting 'Yoshino' Cryptomeria stem cuttings as influenced by growth stage, branch order, and IBA treatment. HortScience 29:1532-1535.

Mackenzie, K.A.D., B.H. Howard, and R.S. Harrison-Murray. 1986. The anatomical relationship between cambial regeneration and root initiation in wounded winter cuttings of the apple rootstock M.26. Annal. Bot. 58:649-661.
Table 1. Effects of wounding of cutting bases and concentration of IBA on percent rooting, and number, length, and fresh and dry weights of roots per cutting on $A$. andrachne basal stem cuttings.

\begin{tabular}{|c|c|c|c|c|c|}
\hline Treatment & $\begin{array}{c}\text { Rooting } \\
(\%)\end{array}$ & No. & $\begin{array}{l}\text { Length } \\
(\mathrm{cm})\end{array}$ & $\begin{array}{c}\text { Fresh wt } \\
(\mathrm{mg})\end{array}$ & $\begin{array}{c}\text { Dry wt } \\
(\mathrm{mg})\end{array}$ \\
\hline \multicolumn{6}{|l|}{ Wounding (W) } \\
\hline Wounded & 50 & 4.3 & 19 & 298 & 140 \\
\hline Not wounded & 18 & 0.8 & 2 & 40 & 17 \\
\hline \multicolumn{6}{|l|}{ Concn (mM) (C) } \\
\hline 24 & 43 & 3.6 & 15 & 226 & 106 \\
\hline 36 & 25 & 1.4 & 6 & 111 & 51 \\
\hline \multicolumn{6}{|l|}{ Significance } \\
\hline W & $* *$ & $* * *$ & $* * *$ & $* * *$ & $* * *$ \\
\hline $\mathrm{C}$ & NS & $*$ & $*$ & NS & NS \\
\hline $\mathrm{W} \times \mathrm{C}$ & NS & NS & NS & NS & NS \\
\hline
\end{tabular}

Table 2. Effects of propagation medium and concentration of IBA on percent rooting, and number, length, and fresh and dry weights of roots on A. andrachne basal stem cuttings.

\begin{tabular}{|c|c|c|c|c|c|}
\hline Treatment & $\begin{array}{c}\text { Rooting } \\
(\%)\end{array}$ & No. & $\begin{array}{c}\text { Length } \\
(\mathrm{cm})\end{array}$ & $\begin{array}{l}\text { Fresh wt } \\
(\mathrm{mg})\end{array}$ & $\begin{array}{c}\text { Dry wt } \\
(\mathrm{mg})\end{array}$ \\
\hline \multicolumn{6}{|l|}{ Medium (M) } \\
\hline Perlite & $64 \mathrm{a}^{\mathrm{z}}$ & $5.0 \mathrm{a}$ & $22 \mathrm{a}$ & $339 \mathrm{a}$ & $153 \mathrm{a}$ \\
\hline 1 Peatmoss : 3 Perlite & $54 \mathrm{ab}$ & $5.0 \mathrm{a}$ & $17 \mathrm{a}$ & $248 \mathrm{a}$ & $113 \mathrm{a}$ \\
\hline 1 Peatmoss : 1 Perlite & $36 \mathrm{bc}$ & $2.0 \mathrm{~b}$ & $8 \mathrm{~b}$ & $120 \mathrm{~b}$ & $54 \mathrm{~b}$ \\
\hline 3 Peatmoss : 1 Perlite & $25 \mathrm{~cd}$ & $1.1 \mathrm{bc}$ & $4 \mathrm{bc}$ & $46 \mathrm{bc}$ & $20 \mathrm{bc}$ \\
\hline Vermiculite & $11 \mathrm{~d}$ & $0.4 \mathrm{c}$ & $1 \mathrm{c}$ & $15 \mathrm{c}$ & $6 \mathrm{c}$ \\
\hline \multicolumn{6}{|l|}{ Concn (mM) (C) } \\
\hline 24 & 44 & 3.4 & 13 & 188 & 85 \\
\hline 36 & 31 & 2.1 & 8 & 119 & 53 \\
\hline \multicolumn{6}{|l|}{ Significance } \\
\hline $\mathrm{M}$ & $* * *$ & $* * *$ & $* * *$ & $* * *$ & $* * *$ \\
\hline $\mathrm{C}$ & NS & $*$ & $*$ & $*$ & $*$ \\
\hline $\mathrm{M} \times \mathrm{C}$ & NS & NS & NS & NS & NS \\
\hline
\end{tabular}

${ }^{\mathrm{z}}$ Mean separation within columns by LSD, $P \leq 0.05$.

${ }^{\mathrm{NS},}{ }^{*},{ }^{* * *}$ Nonsignificant or significant by $P \leq 0.05$ or 0.001 , respectively.

Maynard, B.K. and N.L. Bassuk. 1990. Rooting softwood cuttings of Acer griseum: Promotion by stockplant etiolation, inhibition by catechol. HortScience 25:200-202.

Perry, F.B. Jr. and H.M. Vines. 1972. Propagation of Magnolia grandiflora (L.) cuttings as related to age and growth regulators. J. Amer. Soc. Hort. Sci. 97:753-756.

SAS Institute. 1995. SAS Inst., Cary, N.C.

Stuart, M. 1979. The encyclopedia of herbs and herbalism. Crescent Books, New York.

Teklehaimanot, Z., H. Tomlinson, T. Lemma, and K. Reeves. 1996. Vegetative propagation of Parkia biglobosa (Jacq.) Benth., an undomesticated fruit tree from West Africa. J. Hort. Sci. 71:205-215.

Testolin, R. and C. Vitagliano. 1987. Influence of temperature and applied auxins during winter propagation of kiwifruit. HortScience 22:573574. 